University of Massachusetts Amherst

ScholarWorks@UMass Amherst

\title{
Reversible Actuation via Photoisomerization-Induced Melting of a Semicrystalline Poly(Azobenzene)
}

\author{
Alexa S. Kuenstler \\ University of Massachusetts Amherst \\ Kyle D. Clark \\ University of California, Santa Barbara \\ Javier Read de Alaniz \\ University of California, Santa Barbara \\ Ryan C. Hayward \\ University of Massachusetts Amherst, hayward@umass.edu
}

Follow this and additional works at: https://scholarworks.umass.edu/muri_pubs

Kuenstler, Alexa S.; Clark, Kyle D.; Read de Alaniz, Javier; and Hayward, Ryan C., "Reversible Actuation via Photoisomerization-Induced Melting of a Semicrystalline Poly(Azobenzene)" (2020). ACS Macro Letters. 22.

https://doi.org/10.1021/acsmacrolett.0c00328

This Article is brought to you for free and open access by the MURI on Photomechanical Materials at ScholarWorks@UMass Amherst. It has been accepted for inclusion in Publications by an authorized administrator of ScholarWorks@UMass Amherst. For more information, please contact scholarworks@library.umass.edu. 


\title{
Reversible Actuation via Photoisomerization-Induced Melting of a Semi-Crystalline Poly(Azobenzene)
}

\author{
Alexa S. Kuenstler, ${ }^{1}$ Kyle D. Clark, ${ }^{2}$ Javier Read de Alaniz, ${ }^{2}$ and Ryan C. Hayward ${ }^{1, *}$ \\ ${ }^{1}$ Department of Polymer Science and Engineering, University of Massachusetts Amherst, Amherst, MA 01003 \\ ${ }^{2}$ Department of Chemistry and Biochemistry, University of California Santa Barbara Santa Barbara, CA 93106
}

KEYWORDS photomechanical devices, actuators, semi-crystalline polymers, shape memory

\begin{abstract}
Photoisomerization of azobenzene in polymer matrices is a powerful method to convert photon energy into mechanical work. While most previous studies have focused on incorporating azobenzene within amorphous or liquid crystalline materials, the limited extents of molecular ordering and correspondingly modest enthalpy changes upon switching in such systems has limited the achievable energy densities. In this work, we introduce a semi-crystalline main-chain poly(azobenzene) where photoisomerization is capable of reversibly triggering melting and re-crystallization under essentially isothermal conditions. These materials can be drawn into aligned fibers, yielding optically-driven two-way shape memory actuators capable of reversible bending.
\end{abstract}

Light is a powerful actuation stimulus due to the possibilities offered for specifying complex spatiotemporal responses through patterning of wavelength, mode, and polarization. ${ }^{1-3}$ To convert photon energy into mechanical work, photomechanical actuators are typically composed of a photoactive moiety embedded within a solid matrix, wherein a photochemical ${ }^{4,5}$ or photothermal $^{6}$ effect triggers a macroscopic response. Among the most widely used are azobenzene-based systems, where molecular-scale conformational changes via cis-trans photoisomerization are harnessed to generate mechanical stress. Efforts in this area have largely focused on the incorporation of azobenzene within amorphous polymers ${ }^{7-9}$ and liquid-crystalline networks (LCNs), ${ }^{10-15}$ with the latter being particularly widely used due to the enhanced mechanical response afforded by the coupling of conformational changes of azobenzene to the orientational ordering of LC mesogens. While LCNs present a facile method for fabricating actuators in arbitrary geometries containing a variety of azo-based photoswitches, ${ }^{16-18}$ the low density of incorporated photochromes and modest enthalpy change of a liquid crystalline to isotropic transition $\left(\Delta \mathrm{H}_{\mathrm{ni}} \sim 1-10 \mathrm{~J} \mathrm{~g}^{-1}\right)$ limits their potential work output. Alternatively, crystallization of small molecule azobenzene derivatives can form photomechanical crystals wherein increased elastic moduli and cooperative isomerization offer the potential to dramatically enhance the photomechanical response. ${ }^{19-22}$ However, poor processability of such crystals limits the size and geometry of obtainable materials. Furthermore, these devices are prone to fracture due to the large internal photostresses generated during photoisomerization. ${ }^{23}$

To advance photoactuator performance, novel material systems are needed that combine the processability of polymers with the high density of ordered chromophores found in crystalline systems. One possible platform is semi-crystalline polymers, where assembly of high densities of polymerized chromophores into crystalline lamellae would modulate the crystalline unit cell via isomerization and generate a photoinduced stress. However, while reversible melting of semi-crystalline polymers in shape memory actuators demonstrates the potential of such systems to produce high work outputs driven by the large enthalpy change of melting $\left(\Delta \mathrm{H}_{\mathrm{m}} \sim 10-100 \mathrm{~J} \mathrm{~g}\right.$ $\left.{ }^{1}\right),{ }^{24-26}$ non-photothermal ${ }^{27-31}$ light-driven analogs have yet to be realized. Here, we demonstrate that photoisomerization of azobenzene incorporated in the backbone of semi-crystalline polymers can be harnessed to drive reversible photoactuation. While there exist reports of light-induced crystallization of supramolecular systems ${ }^{32}$ and melting of crystalline small-molecules ${ }^{33-}$ 38 and polymers ${ }^{39-41}$ due to photoisomerization of azobenzene, we show that this phenomenon can be harnessed for optical shape-memory materials capable of undergoing reversible deformation under cycles of illumination.

Though semi-crystalline polymers with azobenzene sidechains have been reported previously, ${ }^{41-43}$ we incorporate azo-

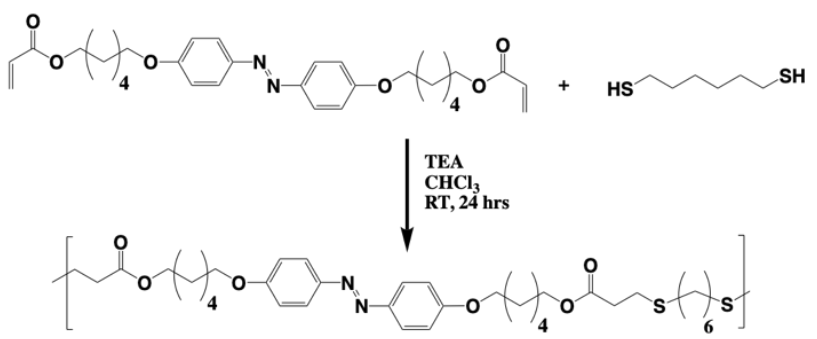

Scheme 1. Preparation of semi-crystalline poly(azobenzene)s 
A.

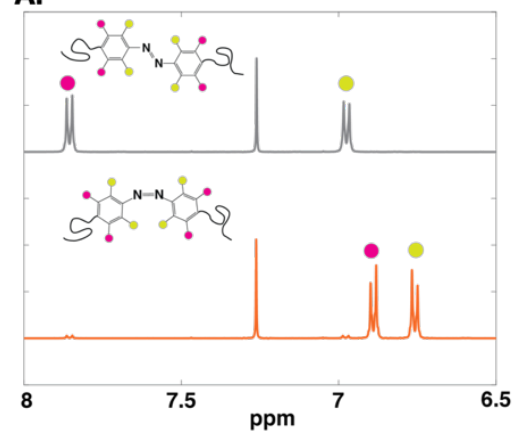

D.

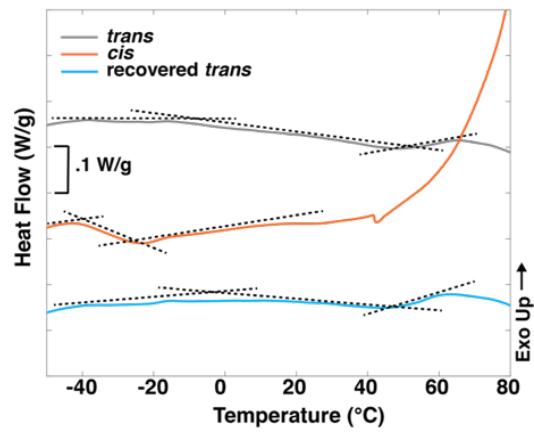

B.

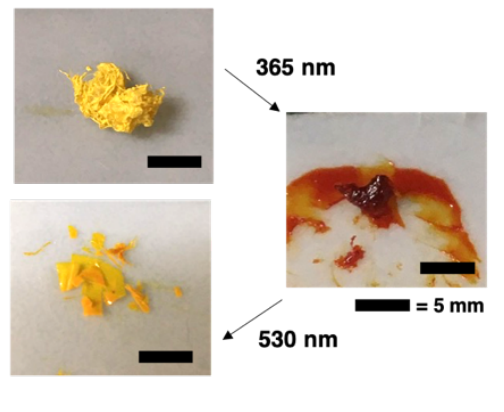

E.

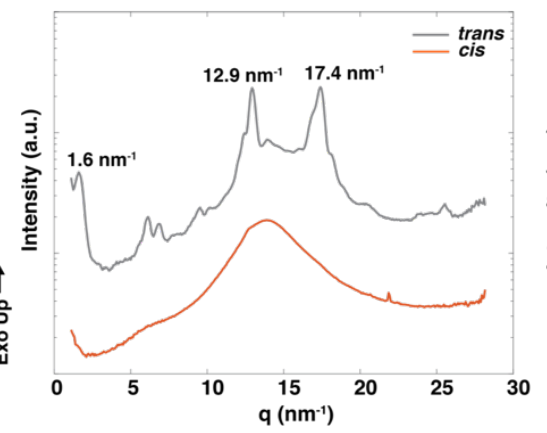

C.

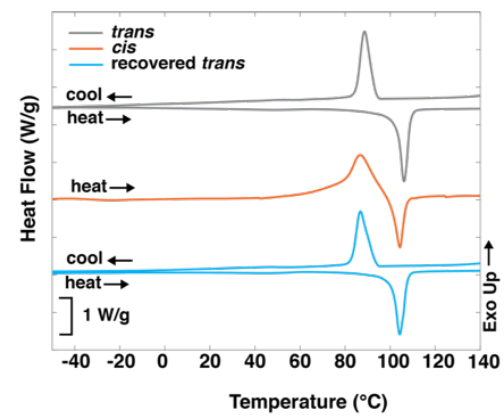

F.

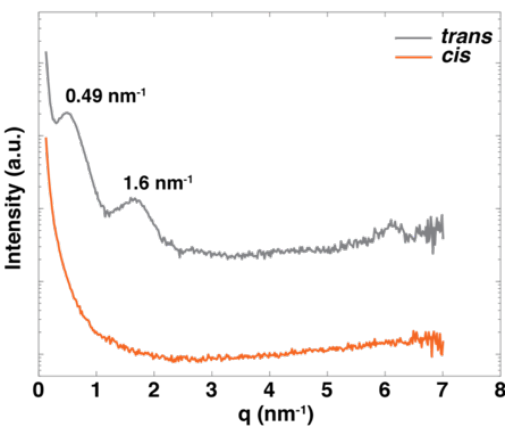

Figure 1. (A) ${ }^{1} \mathrm{H}$ NMR of equilibrated $\mathrm{p}$ (A6) in solution before (top) and after (bottom) $365 \mathrm{~nm}$ light exposure indicates efficient switching from $>99 \%$ trans to $\approx 97 \%$ cis. (B) $\mathrm{p}(\mathrm{A} 6)$ transforms from a solid to a gooey melt following photoisomerization. (C) DSC of the trans polymer (grey trace) shows a melting endotherm at $100{ }^{\circ} \mathrm{C}$ and a crystallization exotherm at $85{ }^{\circ} \mathrm{C}$. When isomerized to the cis form, a crystallization exotherm (orange trace) is observed due to thermal relaxation-driven in situ crystallization followed by a melting exotherm. The initial thermogram is recovered on the following thermal cycle (blue trace). (D) $\mathrm{T}_{\mathrm{g}}$ switches from $\approx 34^{\circ} \mathrm{C}$ to $\approx-35^{\circ} \mathrm{C}$ upon photoisomerization. (E,F) The trans form shows crystalline ordering in WAXS and MAXS that is lost upon isomerization.

benzene into the polymer backbone to strongly couple isomerization with macromolecular conformation using the thiol-Michael addition of an azobenzene diacrylate (A6A) with 1,6-hexane dithiol (Scheme 1). Similar step-growth polymerizations have been previously employed for the synthesis of both mainchain azopolymers ${ }^{44,45}$ and semi-crystalline polymers, ${ }^{46-48}$ but to our knowledge, not one material containing both features. A diacrylate and dithiol (Scheme 1) are combined in a 1.025: 1 molar ratio in chloroform with catalytic triethylamine and stirred for $24 \mathrm{~h}$ at room temperature. The stoichiometry is chosen to preserve acrylate end-groups for subsequent cross-linking (Figure S1). Following polymerization and purification, polymers with number average molecular weight of $20.1 \mathrm{kDa}$ and dispersity of 1.65 (Figure S2) are obtained.

Following thermal equilibration for $24 \mathrm{~h},{ }^{1} \mathrm{H}$ nuclear magnetic resonance (NMR) spectroscopy (Figure 1A) of $\mathrm{p}(\mathrm{A} 6)$ in $\mathrm{CDCl}_{3}$ shows that azobenzene units in $\mathrm{p}(\mathrm{A} 6)$ are in the trans form ( $>99 \%$ ). Upon illumination with $365 \mathrm{~nm}$ light, the trans population isomerizes to a photo-stationary state (PSS) composed of $97 \%$ cis isomers, as indicated by the shift of aromatic protons from 7.8 and $6.9 \mathrm{ppm}$ (trans) to 6.8 and $6.7 \mathrm{ppm}$ (cis) (Figure 1A). No additional isomerization is observed with further light exposure, confirming the PSS is reached. UV-visible (UV-vis) absorption spectra further confirm photo-switching with a dramatic decrease of the trans $\pi, \pi^{*}$ peak and concomitant increase of the cis n, $\pi^{*}$ peak centered at $360 \mathrm{~nm}$ and 530 $\mathrm{nm}$, respectively (Figure S3). Though the slight overlap of the trans and cis absorption peaks (Figure S3) precludes quantitative switching, the significant change in isomer population greatly affects the polymer properties. Before switching, trans$\mathrm{p}(\mathrm{A} 6)$ is a hard yellow solid (Figure 1B); following isomerization, cis-p(A6) is a gooey orange melt. We employ differential scanning calorimetry (DSC) to investigate the cause of such dramatic changes in material properties. Solid-state trans-p(A6) films are initially semi-crystalline, with a melting endotherm upon heating at $\mathrm{T}_{\mathrm{m}}=106{ }^{\circ} \mathrm{C}$ with $\Delta \mathrm{H}_{\mathrm{m}}=67.0 \mathrm{~J} \mathrm{~g}^{-1}$ and a crystallization exotherm at $\mathrm{T}_{\mathrm{c}}=89{ }^{\circ} \mathrm{C}$ and $\Delta \mathrm{H}_{\mathrm{c}}=60.4 \mathrm{~J} \mathrm{~g}^{-1}$ during cooling (Figure $1 \mathrm{C}$, grey). Assuming a purely crystalline sample has a typical value of $\Delta \mathrm{H}_{\mathrm{m}} \approx 150-300 \mathrm{~J} \mathrm{~g}^{-1},{ }^{49}$ we estimate that trans $\mathrm{p}(\mathrm{A} 6)$ is $\sim 20-40 \%$ crystalline. However, when the same sample is photoisomerized in solution, dried, and subjected to an identical thermal treatment, heating produces an exotherm (69.2 $\mathrm{J} \mathrm{g}^{-1}$ ) followed closely by a melting endotherm (64.0 $\mathrm{J} \mathrm{g}^{-1}$ ) at $\mathrm{T}_{\mathrm{m}}$ of trans-p(A6) (Figure 1C, orange), both of comparable magnitude to the corresponding transitions of the trans-p(A6). We attribute the initial exotherm to in-situ crystallization of the polymer as it thermally isomerizes from cis$\mathrm{p}(\mathrm{A} 6)$ to trans-p(A6). On subsequent thermal cycles, the initial thermogram of trans-p(A6) is recovered (Figure 1C, blue), confirming thermal isomerization of cis-p(A6). Furthermore, the glass transition temperature $\left(\mathrm{T}_{\mathrm{g}}\right)$ changes from $\approx 34^{\circ} \mathrm{C}$ in trans$\mathrm{p}(\mathrm{A} 6)$ to $\approx-33^{\circ} \mathrm{C}$ in $c$ is $-\mathrm{p}(\mathrm{A} 6)$, similar to previous observations for side-chain azopolymers. ${ }^{38,50-54}$ Additionally, the $\mathrm{T}_{\mathrm{g}}$ broadens upon crystallization (Figure 1D), likely due to restricted molecular relaxation near the crystalline regions. ${ }^{55,56}$ These thermograms suggest that cis-p(A6) is amorphous and crystallizes upon thermal relaxation to trans-p(A6) providing evidence that crystallinity is modulated via trans-cis photo-isomerization, 

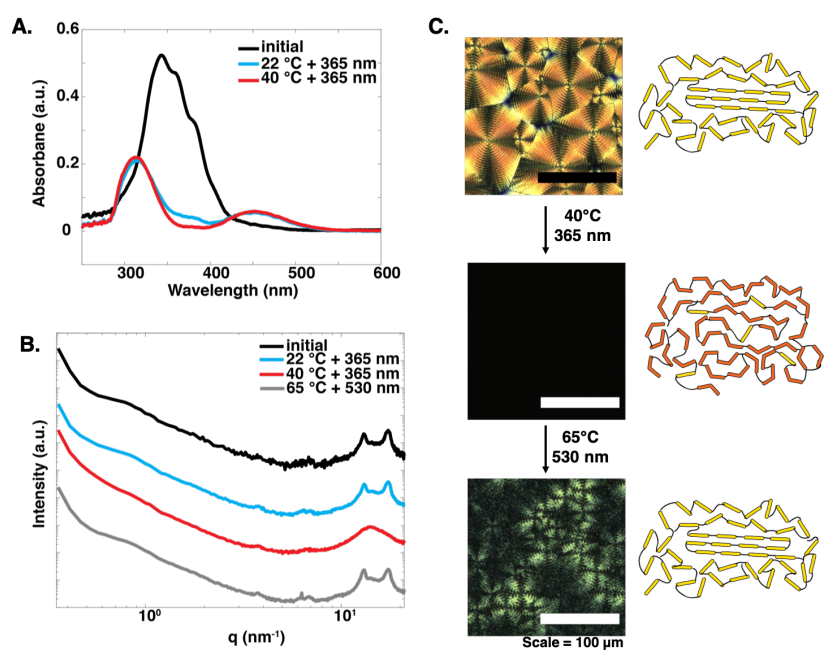

Figure 2. (A) UV-vis spectra of films irradiated at different temperatures. While a large fraction of trans isomer (black curve) switches to cis under $365 \mathrm{~nm}$ illumination at $22{ }^{\circ} \mathrm{C}$ (blue curve), a greater extent of switching is found under illumination at $40^{\circ} \mathrm{C}$ (red curve), as evidenced by a decrease in the trans $\pi, \pi^{*}$ peak at 360 nm. (B) GIWAXS data for thin films subject to different illumination conditions. Persistence of the high $q$ peaks after photo-switching at $22{ }^{\circ} \mathrm{C}$ (blue curve) indicates that no melting occurs, while their disappearance after illumination at $40{ }^{\circ} \mathrm{C}$ indicates photomelting. Upon visible light exposure at $65^{\circ} \mathrm{C}$, recovery of the high $q$ peaks indicates recrystallization. (C) POM images of thin films show an initially spherulitic morphology (top) that is lost upon exposure to UV light at $40{ }^{\circ} \mathrm{C}$ (middle), and significantly restored upon exposure to visible light at $65^{\circ} \mathrm{C}$ (bottom).

similar to how changes in stereochemistry modulate crystallinity in some thermoplastics ${ }^{57-59}$ though rarely controlled using light. ${ }^{60}$ These effects are corroborated by wide-angle (WAXS) and medium-angle X-ray scattering (MAXS) (Figure 1E,F). Prior to photoisomerization, trans-p(A6) shows scattering peaks at $q=17.4 \mathrm{~nm}^{-1}, 12.9 \mathrm{~nm}^{-1}$, and $1.6 \mathrm{~nm}^{-1}$; the highest- $q$ peaks are presumably associated with inter-chain spacings between neighboring polymer chains while the peak at $q=1.6 \mathrm{~nm}^{-}$ ${ }^{1}$ (corresponding to a $d$-spacing of $3.9 \mathrm{~nm}$ ) likely reflects the periodicity along the chain axis. We attribute the scattering peak at $q=0.49 \mathrm{~nm}^{-1}(d=13 \mathrm{~nm})$ to the characteristic spacing between crystalline lamellae. Upon isomerization, the low $q$ peaks disappear while the high $q$ peaks coalesce into one broad peak, indicating a crystalline-to-amorphous phase change.

We next investigate the effect of photoswitching properties on molecular ordering in solid-state thin films. UV-vis spectra of films on quartz confirm that trans-p(A6) (Figure 2A, black) switches to cis-p(A6) (Figure 2A, blue) with a PSS of $\approx 89 \%$ cis isomer (see Supplementary Information) upon exposure to $365 \mathrm{~nm}$ light at $22^{\circ} \mathrm{C}$. Furthermore, trans-p(A6) is recovered upon exposure to $530 \mathrm{~nm}$ light. This process is fatigue-resistant over several cycles (Figure S5), confirming that switching is preserved in the solid state, albeit with a PSS under UV illumination that contains a higher residual trans content $11 \%$ ) than in solution $(3 \%)$. However, when samples are exposed to further UV light at $40{ }^{\circ} \mathrm{C}$, a PSS of $\approx 96 \%$ cis isomer is observed (Figure 2A, red), similar to the solution value. To investigate how solid-state isomerization influences crystalline ordering,

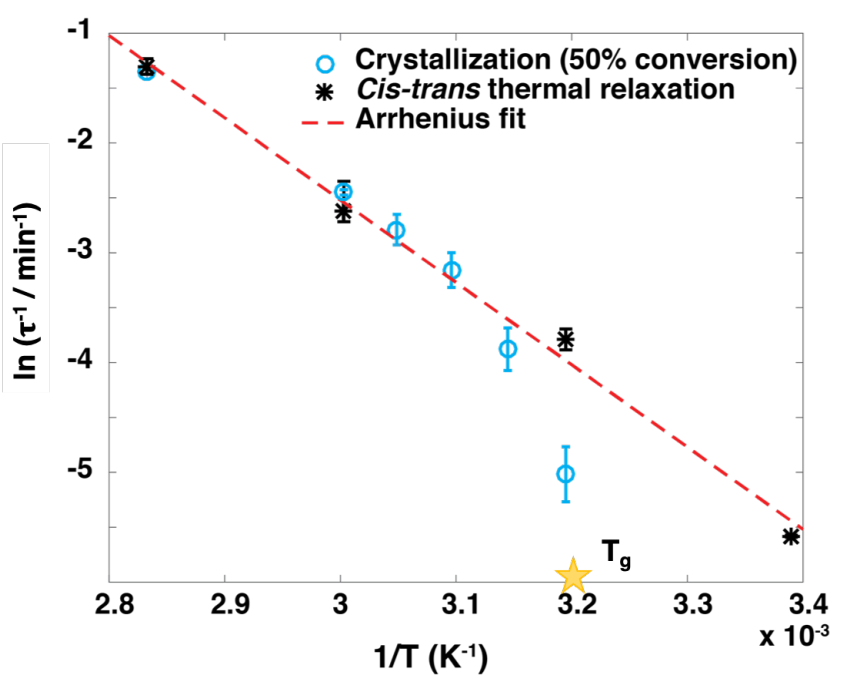

Figure 3 Cis-trans thermal relaxation (black stars) follow Arrhenius kinetics (red dotted line) for all temperatures measured using UV-vis spectroscopy. Isothermal crystallization measurements (blue circles) show that crystallization kinetics follow those of cistrans isomerization at high temperatures but drop significantly faster as $\mathrm{T}_{\mathrm{g}}$ of the trans polymer (yellow star) is approached.

we employ grazing incidence wide-angle scattering (GIWAXS; Figure 2B) and polarized optical microscopy (POM; Figure 2C) on thin films. While trans-p(A6) samples show crystalline ordering as evidenced by peaks at $q=17.4 \mathrm{~nm}^{-1}$ and 12.9 $\mathrm{nm}^{-1}$, negligible change in the scattering profile is observed upon exposure to $365 \mathrm{~nm}$ light at $22{ }^{\circ} \mathrm{C}$ (Figure 2B, blue) despite the substantial degree of trans-cis isomerization observed by UV-vis. However, increased photoswitching upon UV exposure at $40{ }^{\circ} \mathrm{C}$ results in the coalescence of scattering peaks into one broad peak, indicating a loss of crystalline ordering (Figure $2 \mathrm{~B}$, red). While the $q=1.6 \mathrm{~nm}^{-1}$ peak observed in bulk samples is obscured in these scattering patterns due to the large low- $q$ background, a broad peak in this region is observed in trans$\mathrm{p}(\mathrm{A} 6)$ and disappears upon switching to cis-p(A6), consistent with photoisomerization-induced melting.

POM provides further insight into the interplay between isomer population and crystallinity. Initially, trans-p(A6) displays banded spherulites, an optical signature of semi-crystalline polymers (Figure $2 \mathrm{C}$, top). ${ }^{61}$ After $365 \mathrm{~nm}$ light exposure at $\mathrm{T}=$ $40{ }^{\circ} \mathrm{C}$, the spherulites disappear (Figure $2 \mathrm{C}$, middle), indicating photomelting. Notably, this change is due to photoisomerization and not photothermal heating, as IR images show an illumination-induced temperature change of $<5^{\circ} \mathrm{C}$, and thus the sample temperature remains well below $\mathrm{T}_{\mathrm{m}}$ (Figure S4A). However, no morphological change is observed upon UV light exposure at $22{ }^{\circ} \mathrm{C}$ (Figure S4B), consistent with the result from GIWAXS showing persistent crystalline ordering despite photoswitching. Collectively, these data suggest that at room temperature, molecular mobility within the crystalline domains is sufficiently restricted such that isomerization is suppressed and crystalline lamellae are preserved, while the looser packing of polymers in amorphous regions enables these regions to photoisomerize to a PSS similar to the solution-state value. As the temperature is increased, there is sufficient mobility for the azobenzene units within the crystalline domains to isomerize, ${ }^{62}$ as evidenced by an increase in the PSS obtained for the solid films, 
A.
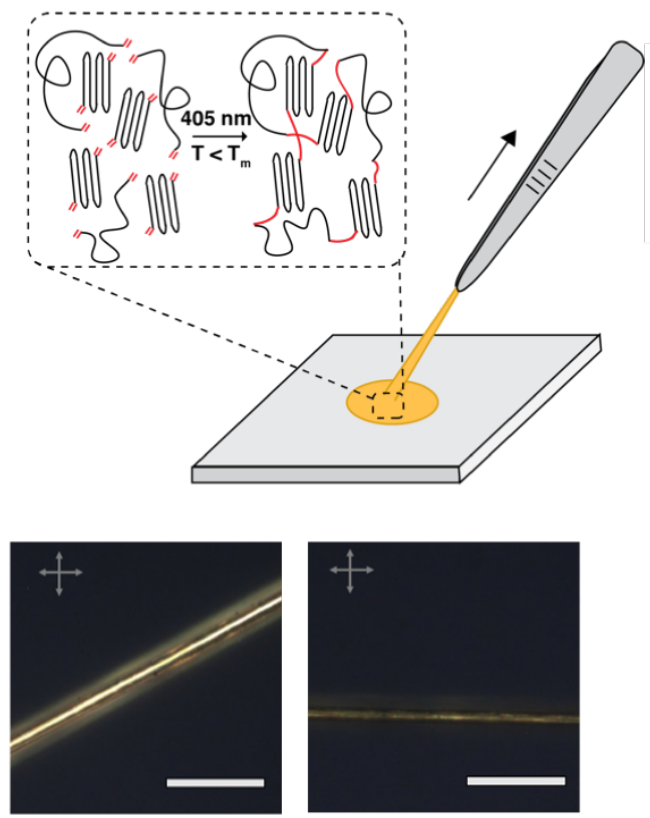

B.
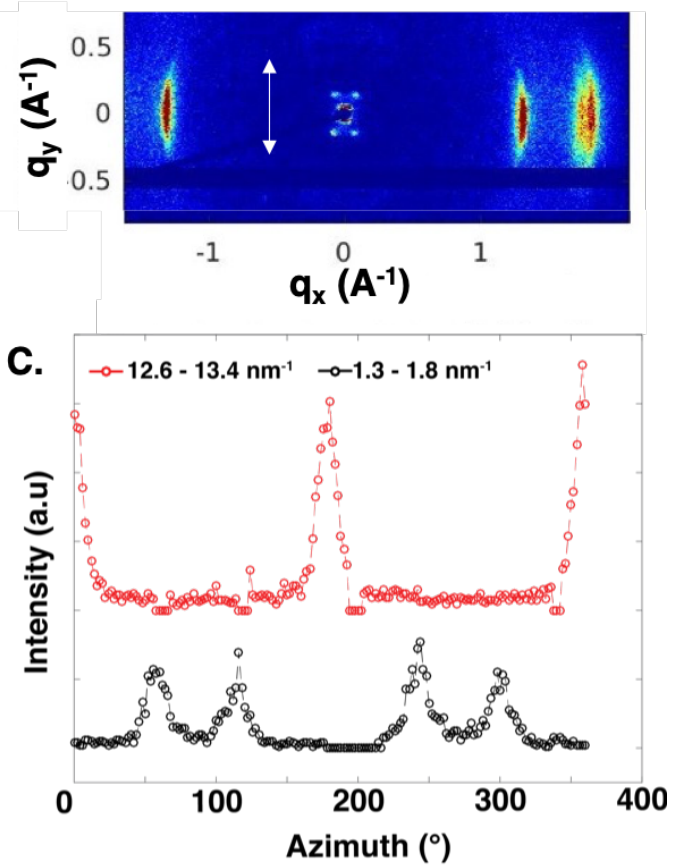

Figure 4. (A) (Top) Fibers are formed by drawing from the melt and photo-crosslinking acrylate end-groups. (Bottom) POM images of fibers at $45^{\circ}$ (left) and $0^{\circ}$ (right) with respect the analyzer indicate a high degree of alignment. (B) Two-dimensional wide-angle X-ray scattering pattern and (C) corresponding plot of intensity vs azimuthal angle in the low- $q$ and high-q regimes indicates chain alignment along the drawing axis (denoted by a white arrow).

and correspondingly for the lamellae to melt as observed using GIWAXS and POM. While birefringence does not re-appear upon exposure to $530 \mathrm{~nm}$ light at $40{ }^{\circ} \mathrm{C}$, indicating a lack of crystallization despite photoswitching (Figure S5), spherulites re-form under visible light exposure at higher temperatures (Figure 2C, bottom).

To study the effect of temperature on re-crystallization, we monitor cis-trans thermal relaxation rates in thin films via UVvis and re-crystallization in cis-p(A6) samples via isothermal DSC experiments (Figure S6). While thermal relaxation is consistent with Arrhenius kinetics across the range of temperatures studied (Figure 3, red dotted line) ${ }^{63}$ crystallization kinetics (black circles) are Arrhenius at high temperatures but decrease significantly faster as the $\mathrm{T}_{\mathrm{g}}$ of trans-p(A6) is approached (yellow star). This suggests that polymer viscosity becomes increasingly important with decreasing temperature. We hypothesize that re-crystallization is suppressed under visible light illumination at low temperatures because cis-trans isomerization increases $\mathrm{T}_{\mathrm{g}}$, thus kinetically trapping the amorphous phase upon vitrification. We note that although the rates of thermal cis-trans isomerization and recrystallization accelerate as temperature is increased, the light exposure time $(\approx 1 \mathrm{~min})$ needed to induce re-crystallization is much less than that needed for thermally-induced re-crystallization below $80{ }^{\circ} \mathrm{C}$. Thus photoswitching, not thermal relaxation, is predominantly responsible for re-crystallization under illumination at sufficient temperatures. At even higher temperatures, we expect that the rate of thermal cis-trans relaxation will exceed the inherent rates of nucleation and growth, though the relative rates of these two phenomena can likely be tuned through modulation of the thermal isomerization kinetics of azobenzene via ortho- or parasubstitutions. ${ }^{64}$

Photoactuators are fabricated by drawing polymer fibers from melts containing $2.5 \mathrm{wt} \%$ photoinitiator (Figure $4 \mathrm{~A}$ ). Crosslinking of acrylate end-groups using $405 \mathrm{~nm}$ light at $80{ }^{\circ} \mathrm{C}$ topologically fixes the crystal alignment and biases melting and re-crystallization along the drawing direction. ${ }^{65,66}$ Weak trans absorption at $405 \mathrm{~nm}$ and increased thermal relaxation limits photoswitching, preserving crystalline orientation during crosslinking (Figure S7). The fibers are insoluble in organic solvents with a broad $\mathrm{T}_{\mathrm{g}}$ of $\approx 35^{\circ} \mathrm{C}$, a Young's modulus of $\mathrm{E}=120 \mathrm{MPa}$ (Figure S8), and are highly oriented as evidenced by the observed anisotropic birefringence using POM (Figure 4A, bottom). Additionally, transmission WAXS measurements reveal that lamellar normal are highly aligned along the drawing direction, as evidenced from the integrated intensity as a function of azimuthal angle with a FWHM in the low- and high- $q$ regimes of $21^{\circ}$ and $17^{\circ}$, respectively (Figure 4B,C). While processing conditions and crosslinking may both influence the degree of crystallinity and crystallite size ${ }^{67}$ these data reveal that crosslinked materials retain the crystalline characteristics of the linear polymers. Further, POM data on crosslinked films (Figure S9) confirm that light-induced melting and recrystallization still occur following crosslinking. Interestingly, aligned fibers show a four-spot scattering pattern at low $q$ which suggests a tilting of the chain axis such as that often found in poly(olefin)s and poly(ester) $\mathrm{s}^{68}$; work is on-going to better understand the crystal structure.

The actuation properties of these devices are studied by monitoring the change in radius of curvature upon illumination in 
A.

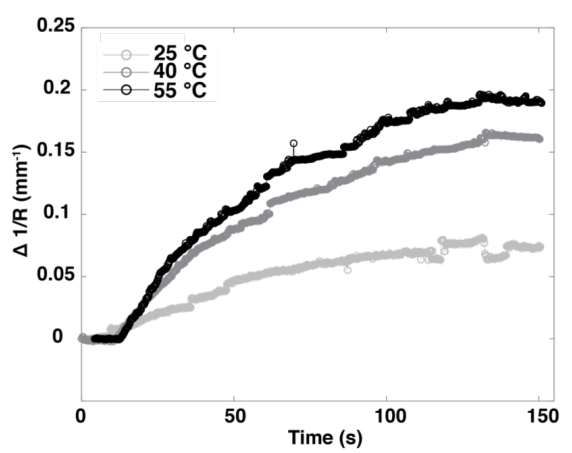

C.

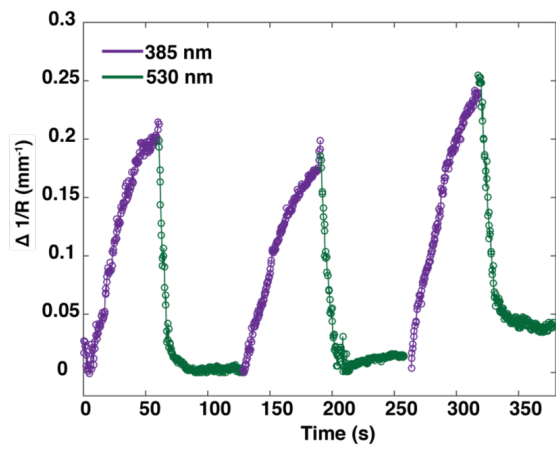

B.

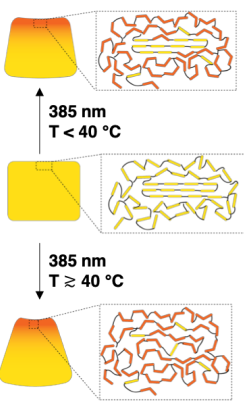

D.

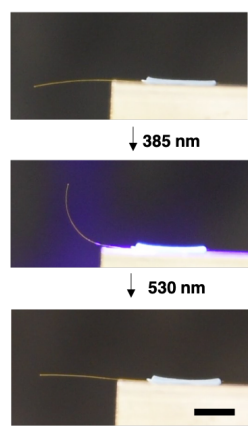

Figure 5. (A) The change in radius of curvature upon illumination increases with increasing temperature. (B) Schematic illustration of a cross-section of a fiber. Below $40{ }^{\circ} \mathrm{C}$, isomerization drives softening via a change in $\mathrm{T}_{\mathrm{g}}$. Photomelting at higher temperatures results in enhanced actuation. (C) Shape-memory cycles for photomelting and re-crystallization upon exposure to UV and green light at $60{ }^{\circ} \mathrm{C}$ and (D) corresponding photographs. Scale bar $=5 \mathrm{~mm}$.

fibers with a diameter of $\mathrm{D}=50 \mu \mathrm{m}$ (Figure 5A). Samples are held isothermally on a heated block and exposed to $385 \mathrm{~nm}$

light, chosen to maximize the penetration depth of illumination $(<6 \mu \mathrm{m}$ for trans-p(A6); see Supplementary Information) while preserving sufficient photoisomerization to induce melting (Figure S10). Illumination with $100 \mathrm{~mW} \mathrm{~cm}^{-2}$ of $385 \mathrm{~nm}$ light at $\mathrm{T}=25^{\circ} \mathrm{C}$ results in a change in curvature of $\Delta \mathrm{R}^{-1} \approx 0.05 \mathrm{~mm}^{-}$ ${ }^{1}$ (Figure 5A, light grey), though no melting is observed at this temperature. We note that similar effects have been attributed to photosoftening due to an isomerization-induced reduction in $\mathrm{T}_{\mathrm{g}}$ in several previous cases, ${ }^{69-72}$ but the specific mechanism at play here requires further study. However, when the fiber is exposed to $385 \mathrm{~nm}$ light at $40{ }^{\circ} \mathrm{C}$, the bending dramatically increases due to photoinduced melting of semi-crystalline trans$\mathrm{p}(\mathrm{A} 6)$ at the top surface of the fiber (Figure 5B, bottom), with a nearly three-fold increase in the radius of curvature compared to that generated from a change in $\mathrm{T}_{\mathrm{g}}$ alone (Figure 5A, dark grey). Thermal images (Figure S11) reveal a modest temperature change significantly below that required for photothermal melting. Further, as heat transfer is expected to minimize the temperature difference maintained across such a thin fiber, photothermal heating is unlikely to be responsible for the observed bending behavior. A slight increase in the radius of curvature is observed upon UV irradiation at $55{ }^{\circ} \mathrm{C}$, presumably due to additional entropic recovery of the polymer chains. Finally, reversible actuation is observed upon sequential illumination with
UV light (Figure 5C, purple) and green light (Figure 5C, green) for $1 \mathrm{~min}$ at $60{ }^{\circ} \mathrm{C}$; this cycle can be repeated several times, demonstrating that isomerization-induced melting and recrystallization can be harnessed for shape-memory in an analogous way to thermally-actuated systems. We estimate that the work output for photoinduced melting is $\mathrm{W} \approx 0.2 \mathrm{~kJ} \mathrm{~m}^{-3}$ based on a photo-induced strain of $\varepsilon \approx 1 \%$ and a modulus of $\mathrm{E} \approx 120 \mathrm{MPa}$ (see Supporting Information). This is comparable to LC-based photoactuators, which exhibit specific work values of $\sim 0.1-1$ $\mathrm{kJ} \mathrm{m}^{-3}$ and where light penetration over $\sim 100-1000$ seconds typically dictates deformation kinetics. ${ }^{3,13,14,73}$ However, actuation in azobenzene systems is dependent on many factors, most notably non-negligible photothermal effects. ${ }^{74,75}$ Here, the work output is predominantly photochemically-mediated and limited by the small penetration depth relative to the fiber diameter. We expect that photomechanical performance could be substantially enhanced with uniform light penetration through-thickness, for example by the use of negative chromophores. ${ }^{76}$

In conclusion, we have developed a facile method to synthesize semi-crystalline main-chain azopolymers and demonstrated that these materials can reversibly melt and re-crystallize upon nearly athermal photoisomerization. Assembly of these materials into aligned fibers yields reversible photoactuators capable of generating mechanical work via photomelting. This approach to light-responsive materials presents new opportunities in the field of photoaddressable devices.

\section{ASSOCIATED CONTENT}

\section{Supporting Information}

The Supporting Information is available free of charge on the ACS Publications website.

\section{AUTHOR INFORMATION}

\section{Corresponding Author}

* Ryan Hayward - Department of Polymer Science and Engineering, University of Massachusetts Amherst, Amherst, MA 01003. Email: hayward@umass.edu

\section{Author Contributions}

The manuscript was written through contributions of all authors.

\section{Funding Sources}

Support for this work was provided by the Office of Naval Research through the MURI on Photomechanical Materials (ONR N00014-18-1-2624).

\section{Notes}

Any additional relevant notes should be placed here.

\section{ACKNOWLEDGMENT}

The authors thank Dr. Wenwen Xu, Hantao Zhou, and Kevin Korner for helpful discussions and Robert Enright for assistance with GIWAXS.

\section{REFERENCES}

Han, D. D.; Zhang, Y. L.; Ma, J. N.; Liu, Y. Q.; Han, B.; Sun, H. B. Light-Mediated Manufacture and Manipulation of Actuators. Adv. Mater. 2016, 28 (38), 8328-8343. 
Yang, M.; Yuan, Z.; Liu, J.; Fang, Z.; Fang, L.; Yu, D.; Li, Q. Photoresponsive Actuators Built from Carbon-Based Soft Materials. Adv. Opt. Mater. 2019, 7 (16), 1-30.

(3) White, T. J. Photomechanical Materials, Composites, and Systems: Wireless Transduction of Light Into Work, 1st ed.; White, T. J., Ed.; John Wiley \& Sons, Ltd.: Hoboken, 2017.

(4) Boelke, J.; Hecht, S. Designing Molecular Photoswitches for Soft Materials Applications. $A d v$. Opt. Mater. 2019, 1900404, 1900404.

(5) Nie, H.; Self, J. L.; Kuenstler, A. S.; Hayward, R. C.; Read de Alaniz, J. Multiaddressable Photochromic Architectures: From Molecules to Materials. Adv. Opt. Mater. 2019, 7 (16), 1900224.

(6) Bisoyi, H. K.; Urbas, A. M.; Li, Q. Soft Materials Driven by Photothermal Effect and Their Applications. Adv. Opt. Mater. 2018, 6, 1800458.

Wang, D. H.; Min Lee, K.; Yu, Z.; Koerner, H.; Vaia, R. A.; White, T. J.; Tan, L. S. Photomechanical Response of Glassy Azobenzene Polyimide Networks. Macromolecules 2011, 44 (10), 3840-3846.

(8) Lee, K. M.; Wang, D. H.; Koerner, H.; Vaia, R. A.; Tan, L.-S.; White, T. J. Enhancement of Photogenerated Mechanical Force in AzobenzeneFunctionalized Polyimides. Angew. Chemie 2012, 124 (17), 4193-4197.

(9) Wang, D. H.; Wie, J. J.; Lee, K. M.; White, T. J.; Tan, L. S. Impact of Backbone Rigidity on the Photomechanical Response of Glassy, AzobenzeneFunctionalized Polyimides. Macromolecules 2014, 47 (2), 659-667.

(10) Barrett, C. J.; Mamiya, J. I.; Yager, K. G.; Ikeda, T. Photo-Mechanical Effects in AzobenzeneContaining Soft Materials. Soft Matter 2007, 3 (10), 1249-1261.

(11) White, T. J.; Broer, D. J. Programmable and Adaptive Mechanics with Liquid Crystal Polymer Networks and Elastomers. Nat. Mater. 2015, 14 (11), 1087-1098.

(12) Pang, X.; Lv, J. an; Zhu, C.; Qin, L.; Yu, Y. Photodeformable Azobenzene-Containing Liquid Crystal Polymers and Soft Actuators. Adv. Mater. 2019, 31 (52), 1-26.

(13) Van Oosten, C. L.; Harris, K. D.; Bastiaansen, C. W. M.; Broer, D. J. Glassy Photomechanical LiquidCrystal Network Actuators for Microscale Devices. Eur. Phys. J. E 2007, 23 (3), 329-336.

(14) Ahn, S. K.; Ware, T. H.; Lee, K. M.; Tondiglia, V. P.; White, T. J. Photoinduced Topographical Feature Development in Blueprinted AzobenzeneFunctionalized Liquid Crystalline Elastomers. $A d v$. Funct. Mater. 2016, 26 (32), 5819-5826.

(15) Aßhoff, S. J.; Lancia, F.; Iamsaard, S.; Matt, B.;
Kudernac, T.; Fletcher, S. P.; Katsonis, N. HighPower Actuation from Molecular Photoswitches in Enantiomerically Paired Soft Springs. Angew. Chemie - Int. Ed. 2017, 56 (12), 3261-3265.

(16) Gelebart, A. H.; Jan Mulder, D.; Varga, M.; Konya, A.; Vantomme, G.; Meijer, E. W.; Selinger, R. L. B.; Broer, D. J. Making Waves in a Photoactive Polymer Film. Nature 2017, 546 (7660), 632-636.

(17) Iamsaard, S.; Anger, E.; Aßhoff, S. J.; Depauw, A.; Fletcher, S. P.; Katsonis, N. Fluorinated Azobenzenes for Shape-Persistent Liquid Crystal Polymer Networks. Angew. Chemie - Int. Ed. 2016, 55 (34), 9908-9912.

(18) Donovan, B. R.; Matavulj, V. M.; Ahn, S. kyun; Guin, T.; White, T. J. All-Optical Control of Shape. Adv. Mater. 2019, 31 (2), 1805750.

(19) Koshima, H.; Ojima, N.; Uchimoto, H. Mechanical Motion of Azobenzene Crystals upon Photoirradiation. J. Am. Chem. Soc. 2009, 131 (20), 6890-6891.

(20) Bushuyev, O. S.; Singleton, T. A.; Barrett, C. J. Fast, Reversible, and General Photomechanical Motion in Single Crystals of Various Azo Compounds Using Visible Light. Adv. Mater. 2013, 25 (12), 17961800.

(21) Taniguchi, T.; Asahi, T.; Koshima, H. Photomechanical Azobenzene Crystals. Crystals 2019, 9 (9), 1-14.

(22) Bushuyev, O. S.; Singleton, T. A.; Barrett, C. J. Fast, Reversible, and General Photomechanical Motion in Single Crystals of Various Azo Compounds Using Visible Light. Adv. Mater. 2013, 25 (12), 17961800.

(23) Kim, T.; Zhu, L.; Al-Kaysi, R. O.; Bardeen, C. J. Organic Photomechanical Materials. ChemPhysChem 2014, 15 (3), 400-414.

(24) Lendlein, A.; Gould, O. E. C. Reprogrammable Recovery and Actuation Behaviour of ShapeMemory Polymers. Nat. Rev. Mater. 2019, 4 (2), 116-133.

(25) Hu, J.; Zhu, Y.; Huang, H.; Lu, J. Recent Advances in Shape-Memory Polymers: Structure, Mechanism, Functionality, Modeling and Applications. Prog. Polym. Sci. 2012, 37 (12), 1720-1763.

(26) Anthamatten, M.; Roddecha, S.; Li, J. Energy Storage Capacity of Shape-Memory Polymers. Macromolecules 2013, 46 (10), 4230-4234.

(27) Koerner, H.; Price, G.; Pearce, N. A.; Alexander, M.; Vaia, R. A. Remotely Actuated Polymer Nanocomposites - Stress-Recovery of CarbonNanotube-Filled Thermoplastic Elastomers. Nat. Mater. 2004, 3 (2), 115-120.

(28) Zhang, H.; Xia, H.; Zhao, Y. Optically Triggered and Spatially Controllable Shape-Memory PolymerGold Nanoparticle Composite Materials. J. Mater. 
Chem. 2012, 22 (3), 845-849.

Ge, F.; Lu, X.; Xiang, J.; Tong, X.; Zhao, Y. An Optical Actuator Based on Gold-NanoparticleContaining Temperature-Memory Semicrystalline Polymers. Angew. Chemie - Int. Ed. 2017, 56 (22), 6126-6130.

(30) Wang, K.; Zhu, X. X. Two-Way Reversible Shape Memory Polymers Containing Polydopamine Nanospheres: Light Actuation, Robotic Locomotion, and Artificial Muscles. ACS Biomater. Sci. Eng. 2018, 4 (8), 3099-3106.

(31) Verpaalen, R. C. P.; Varghese, S.; Froyen, A.; Pilz da Cunha, M.; Pouderoijen, M. J.; Severn, J. R.; Bhatti, M. R.; Peijs, T.; Bastiaansen, C. W. M.; Debije, M. G.; et al. Fast, Light-Responsive, MetalLike Polymer Actuators Generating High Stresses at Low Strain. Matter 2020, 1-13.

(32) Shin, S.; Menk, F.; Kim, Y.; Lim, J.; Char, K.; Zentel, R.; Choi, T. L. Living Light-Induced Crystallization-Driven Self-Assembly for Rapid Preparation of Semiconducting Nanofibers. J. Am. Chem. Soc. 2018, 140 (19), 6088-6094.

(33) Hoshino, M.; Uchida, E.; Norikane, Y.; Azumi, R.; Nozawa, S.; Tomita, A.; Sato, T.; Adachi, S. I.; Koshihara, S. Y. Crystal Melting by Light: X-Ray Crystal Structure Analysis of an Azo Crystal Showing Photoinduced Crystal-Melt Transition. $J$. Am. Chem. Soc. 2014, 136 (25), 9158-9164.

(34) Akiyama, H.; Kihara, H.; Yoshida, M. Photoinduced Crystal-to-Liquid Phase Transitions of Azobenzene Derivatives and Their Application in Photolithography Processes through a Solid Liquid Patterning. Org. Lett. 2014, 16 (19), 50125015.

(35) Akiyama, H.; Yoshida, M. Photochemically Reversible Liquefaction and Solidification of Single Compounds Based on a Sugar Alcohol Scaffold with Multi Azo-Arms. Adv. Mater. 2012, 24 (17), 23532356.

(36) Uchida, E.; Sakaki, K.; Nakamura, Y.; Azumi, R.; Hirai, Y.; Akiyama, H.; Yoshida, M.; Norikane, Y. Control of the Orientation and Photoinduced Phase Transitions of Macrocyclic Azobenzene. Chem. - A Eur. J. 2013, 19 (51), 17391-17397.

(37) Uchida, E.; Azumi, R.; Norikane, Y. Light-Induced Crawling of Crystals on a Glass Surface. Nat. Commun. 2015, 6 (1), 1-7.

(38) Xu, W. C.; Sun, S.; Wu, S. Photoinduced Reversible Solid-to-Liquid Transitions for Photoswitchable Materials. Angew. Chemie - Int. Ed. 2019, 58 (29), 9712-9740.

(39) Zha, R. H.; Vantomme, G.; Berrocal, J. A.; Gosens, R.; De Waal, B.; Meskers, S.; Meijer, E. W. Photoswitchable Nanomaterials Based on Hierarchically Organized Siloxane Oligomers. $A d v$.
Funct. Mater. 2018, 28 (1), 1703952.

(40) Appiah, C.; Woltersdorf, G.; Pérez-Camargo, R. A.; Müller, A. J.; Binder, W. H. Crystallization Behavior of Precision Polymers Containing Azobenzene Defects. Eur. Polym. J. 2017, 97, 299 307.

(41) Shin, J.; Sung, J.; Kang, M.; Xie, X.; Lee, B.; Lee, K. M.; White, T. J.; Leal, C.; Sottos, N. R.; Braun, P. V.; et al. Light-Triggered Thermal Conductivity Switching in Azobenzene Polymers. Proc. Natl. Acad. Sci. 2019, 116 (17), 201817082.

Natansohn, A.; Rochon, P.; Pézolet, M.; Audet, P.; Brown, D.; To, S. Azo Polymers for Reversible Optical Storage. 4. Cooperative Motion of Rigid Groups in Semicrystalline Polymers. Macromolecules 1994, 27 (9), 2580-2585.

(43) Kidowaki, M.; Fujiwara, T.; Ichimura, K. Extraordinarily Thermostable Photodichroism of Poly(4-Cyano-4'-Methacryloyloxyazobenzene)

Films. Chem. Lett. 1999, 28 (7), 641-642.

(44) Ahn, S. K.; Ware, T. H.; Lee, K. M.; Tondiglia, V. P.; White, T. J. Photoinduced Topographical Feature Development in Blueprinted AzobenzeneFunctionalized Liquid Crystalline Elastomers. $A d v$. Funct. Mater. 2016, 26 (32), 5819-5826.

(45) Fang, L.; Zhang, H.; Li, Z.; Zhang, Y.; Zhang, Y.; Zhang, H. Synthesis of Reactive Azobenzene MainChain Liquid Crystalline Polymers via Michael Addition Polymerization and Photomechanical Effects of Their Supramolecular Hydrogen-Bonded Fibers. Macromolecules 2013, 46 (19), 7650-7660.

(46) Kwasny, M. T.; Watkins, C. M.; Posey, N. D.; Matta, M. E.; Tew, G. N. Functional Polyethylenes with Precisely Placed Thioethers and Sulfoniums through Thiol-Ene Polymerization. Macromolecules 2018, 51 (11), 4280-4289.

(47) Childress, K. K.; Alim, M. D.; Hernandez, J. J.; Stansbury, J. W.; Bowman, C. N. Additive Manufacture of Lightly Crosslinked Semicrystalline Thiol-Enes for Enhanced Mechanical Performance. Polym. Chem. 2019, 11 (1), 39-46.

(48) Alim, M. D.; Childress, K. K.; Baugh, N. J.; Martinez, A. M.; Davenport, A.; Fairbanks, B. D.; McBride, M. K.; Worrell, B. T.; Stansbury, J. W.; McLeod, R. R.; et al. A Photopolymerizable Thermoplastic with Tunable Mechanical Performance. Mater. Horizons 2020, 7, 835-842.

(49) Mandelkern, L. Crystallization of Polymers, 2nd ed.; Cambridge University Press, 2002.

(50) Petr, M.; Helgeson, M. E.; Soulages, J.; McKinley, G. H.; Hammond, P. T. Rapid Viscoelastic Switching of an Ambient Temperature Range Photo-Responsive Azobenzene Side Chain Liquid Crystal Polymer. Polymer (Guildf). 2013, 54 (12), 2850-2856. 
(51) Zhou, H.; Xue, C.; Weis, P.; Suzuki, Y.; Huang, S.; Koynov, K.; Auernhammer, G. K.; Berger, R.; Butt, H. J.; Wu, S. Photoswitching of Glass Transition Temperatures of Azobenzene-Containing Polymers Induces Reversible Solid-to-Liquid Transitions. Nat. Chem. 2017, 9 (2), 145-151.

(52) Weis, P.; Tian, W.; Wu, S. Photoinduced Liquefaction of Azobenzene-Containing Polymers. Chem. - A Eur. J. 2018, 24 (25), 6494-6505.

(53) Ito, S.; Yamashita, A.; Akiyama, H.; Kihara, H.; Yoshida, M. Azobenzene-Based (Meth)Acrylates: Controlled Radical Polymerization, Photoresponsive Solid-Liquid Phase Transition Behavior, and Application to Reworkable Adhesives. Macromolecules 2018, 51 (9), 32433253.

(54) Zhou, Y.; Chen, M.; Ban, Q.; Zhang, Z.; Shuang, S.; Koynov, K.; Butt, H. J.; Kong, J.; Wu, S. LightSwitchable Polymer Adhesive Based on Photoinduced Reversible Solid-to-Liquid Transitions. ACS Macro Lett. 2019, 8 (8), 968-972.

(55) Newman, S.; Cox, W. P. The Glass Temperature of Semicrystalline Polymers. J. Polym. Sci. 1960, 46 (147), 29-49.

(56) Boyd, R. H. Relaxation Processes in Crystalline Polymers: Experimental Behaviour - a Review. Polymer (Guildf). 1985, 26 (3), 323-347.

(57) Worch, J. C.; Prydderch, H.; Jimaja, S.; Bexis, P.; Becker, M. L.; Dove, A. P. Stereochemical Enhancement of Polymer Properties. Nat. Rev. Chem. 2019, 3 (9), 514-535.

(58) Anandakumaran, K.; Kuo, C. C.; Mukherji, S. Crystallization of Trans-1,4-Polyisoprene. J. Polym. Sci. Part B-Polymer Phys. 1982, 20 (9), 1669-1676.

(59) Yao, K.; Nie, H.; Liang, Y.; Qiu, D.; He, A. Polymorphic Crystallization Behaviors in Cis-1,4Polyisoprene/Trans-1,4-Polyisoprene Blends. Polymer (Guildf). 2015, 80, 259-264.

(60) Wan, Z. Q.; Ren, W. M.; Yang, S.; Li, M. R.; Gu, G. G.; Lu, X. B. Reversible Transformation between Amorphous and Crystalline States of Unsaturated Polyesters by Cis-Trans Isomerization. Angew. Chemie - Int. Ed. 2019, 58 (49), 17636-17640.

(61) Lovinger, A. J. Twisted Crystals and the Origin of Banding in Spherulites of Semicrystalline Polymers. Macromolecules 2020, 53 (3), 741-745.

(62) Eisenbach, C. Effect of Polymer Matrix on the Cistrans Isomerization of Azobenzene Residues in Bulk Polymers. Die Makromol. Chemie 1978, 179 (10), 2489-2506.

(63) Barrett, C.; Natansohn, A.; Rochon, P. Cis-Trans Thermal Isomerization Rates of Bound and Doped Azobenzenes in a Series of Polymers. Chem. Mater. 1995, 7 (5), 899-903.

(64) Bandara, H. M. D.; Burdette, S. C.
Photoisomerization in Different Classes of Azobenzene. Chem. Soc. Rev. 2012, 41 (5), 1809 1825.

(65) Meng, Y.; Jiang, J.; Anthamatten, M. Shape Actuation via Internal Stress-Induced Crystallization of Dual-Cure Networks. ACS Macro Lett. 2015, 4 (1), 115-118.

(66) Xie, H.; Yang, K. K.; Wang, Y. Z. Photo-CrossLinking: A Powerful and Versatile Strategy to Develop Shape-Memory Polymers. Prog. Polym. Sci. 2019, 95, 32-64.

(67) Lewis, C. L.; Meng, Y.; Anthamatten, M. WellDefined Shape-Memory Networks with High Elastic Energy Capacity. Macromolecules 2015, 48 (14), $4918-4926$.

(68) Lotz, B.; Miyoshi, T.; Cheng, S. Z. D. 50th Anniversary Perspective: Polymer Crystals and Crystallization: Personal Journeys in a Challenging Research Field. Macromolecules 2017, 50 (16), 5995-6025.

(69) Yue, Y.; Norikane, Y.; Azumi, R.; Koyama, E. Light-Induced Mechanical Response in Crosslinked Liquid-Crystalline Polymers with Photoswitchable Glass Transition Temperatures. Nat. Commun. 2018, 9 (1), 1-8.

(70) Hu, J.; Li, X.; Ni, Y.; Ma, S.; Yu, H. A Programmable and Biomimetic Photo-Actuator: A Composite of a Photo-Liquefiable Azobenzene Derivative and Commercial Plastic Film. J. Mater. Chem. C 2018, 6 (40), 10815-10821.

(71) Chen, M.; Yao, B.; Kappl, M.; Liu, S.; Yuan, J.; Berger, R.; Zhang, F.; Butt, H. J.; Liu, Y.; Wu, S. Entangled Azobenzene-Containing Polymers with Photoinduced Reversible Solid-to-Liquid Transitions for Healable and Reprocessable Photoactuators. Adv. Funct. Mater. 2019, 30 (4), 1906752.

(72) Zhang, X.; Zhu, C.; Xu, B.; Qin, L.; Wei, J.; Yu, Y. Rapid, Localized, and Athermal Shape Memory Performance Triggered by Photoswitchable Glass Transition Temperature. ACS Appl. Mater. Interfaces 2019, 11 (49), 46212-46218.

(73) Yamada, M.; Kondo, M.; Mamiya, J.; Yu, Y.; Kinoshita, M.; Barrett, C. J.; Ikeda, T. Photomobile Polymer Materials: Towards Light-Driven Plastic Motors. Angew. Chemie Int. Ed. 2008, 47 (27), 4986-4988.

(74) Lee, K. M.; White, T. J. Photochemical Mechanism and Photothermal Considerations in the Mechanical Response of Monodomain, AzobenzeneFunctionalized Liquid Crystal Polymer Networks. Macromolecules 2012, 45 (17), 7163-7170.

(75) Dawson, N. J.; Kuzyk, M. G.; Neal, J.; Luchette, P.; Palffy-Muhoray, P. Experimental Studies of the Mechanisms of Photomechanical Effects in a 
Nematic Liquid Crystal Elastomer in a Photomechanical Optical Device Geometry. J. Opt. Soc. Am. B 2011, 28 (9), 2134-2141.

(76) Aiken, S.; Edgar, R. J. L.; Gabbutt, C. D.; Heron, B. M.; Hobson, P. A. Negatively Photochromic Organic Compounds: Exploring the Dark Side. Dye. Pigment. 2018, 149, 92-121. 